\title{
Influence of Polypropylene Fibres on Concrete Properties
}

\author{
Tarteel Awad Hajali Ahmed *, Dr. Osama Mohammed Ahmed Daoud** \\ *( Civil Engineering Department, Khartoum University, Khartoum) \\ ** (Building and Road Research Institute, Khartoum University, Khartoum)
}

\begin{abstract}
This paper deals with the influence of addition of various proportions of polypropylene fibres on the properties of fresh and hardened concrete. The objective of this study is to find optimum percentage of Polypropylene fibre content between $0.1 \%$ and $0.5 \%$ by volume of concrete. An experimental program was carried out to explore its effects on fresh and hardened concrete properties. The slump test was conducted for fresh properties of concrete, also concrete specimens were tested at different age level for mechanical properties of concrete, namely, compressive strength, split tensile strength, flexural strength and modulus of elasticity. The results showed that the workability of concrete decreased with the addition of polypropylene fibres. Results also showed a reduction in modulus of elasticity after 28 day when compared to the reference concrete i.e. without fibre. An increase in flexural strength at $0.5 \%$ percentage of polypropylene fibre reinforced concrete was observed when compared to the reference concrete. Also a marked increase in splitting tensile strength was observed for all fibre percentages at 28 day.
\end{abstract}

Keywords: Polypropylene Fibre, PPFRC, Splitting tensile strength, Flexural Strength, FRC.

\section{Introduction}

Concrete is brittle material with low tensile strength and low strain capacity that result in low resistance to cracking. To improve such properties Polypropylene fibre reinforced concrete (PPFRC) was used. Polypropylene fibres are actually man-made synthetic fibres resulted from research and development in the petrochemical and textile industries. These fibres derived from organic polymers which are available in a variety of formulations [1].

\section{a. Manufacture of Polypropylene Fibre:}

Polypropylene Fibres are manufactured using conventional melt spinning. PPF are thermo plastics produced from Propylene gas, which is obtained from the petroleum by products or cracking of natural gas feed stocks. Propylene polymerizes to form long polymer chain under high temperature and pressure. However, PPF with controlled configurations of molecules can be made only using special catalysts. Polypropylene fibres were formerly known as Steal the, These are micro reinforcement fibres and are 100\% virgin homopolymer polypropylene graded monofilament fibres. They contain no reprocessed Olifin materials. The raw material of polypropylene is derived from monomeric $\mathrm{C}_{3} \mathrm{H}_{6}$ which is purely a hydrocarbon [2].

b. Types of PPF are Monofilament, Microfilament and Fibrillated fibres [3].

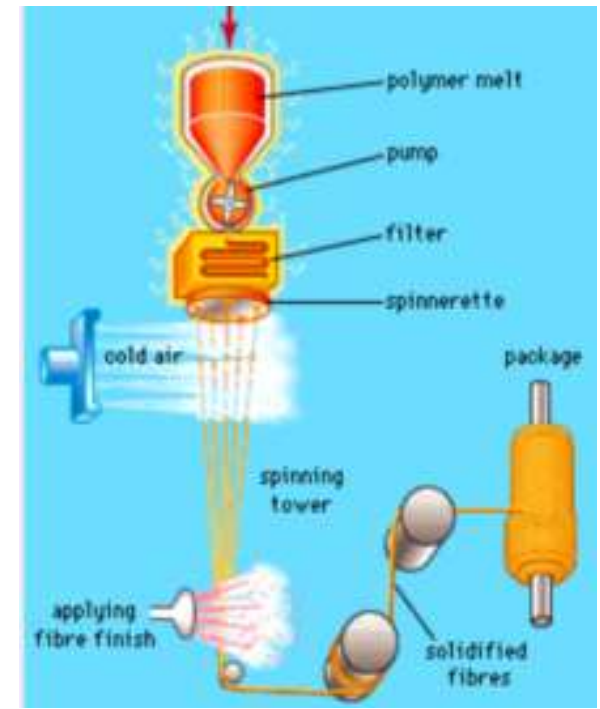

Figure 1: Melt spinning process 


\section{c. Uniform Dispersion of Fibres:}

Mixing of FRC can be accomplished by several methods, the choice of method depending on the job requirements and the facilities available. It is important to have a uniform dispersion of the fibre to prevent the segregation or balling of the fibres during mixing. Before mixing the concrete, the fibre length, amount and design mix variables are adjusted to prevent the fibres from balling [4].

\section{d. Failure modes of FRC:}

The failure modes of FRC are either by bond failure between fibre or matrix or material failure [5].

\section{e. Purposes and Advantages:}

The principal reason for incorporating short discrete fibre into a cement matrix is to reduce cracking in the elastic range, inhibits plastic settlement cracking, control plastic shrinkage cracking, lowers water migration in concrete and control bleeding, increase the tensile strength, improves flexural properties of concrete and increase deformation capacity and the toughness of the resultant composite, increase abrasion resistance significantly and improve fire resistances of concrete [4]. Improving fatigue performance is one of the primary reasons for the extensive use of PPFRC in pavements, bridge decks, offshore structures and machine foundation, where the composite is subjected to cyclically Varying load during its lifetime [6].

Polypropylene is inexpensive, inert in high $\mathrm{pH}$ cementitious environment and easy to disperse [7]. It has a melting point of $165^{\circ} \mathrm{C}$ and can withstand temperatures of over $100^{\circ} \mathrm{Cfor}$ short periods of time before softening. The fibre is susceptible to degradation by UV radiation (sunlight) and oxygen; however, in the concrete matrix this problem is eliminated [8].Polypropylene is in the polyolefin family of chemicals. Chemically inert, it will not rust, corrode or rot, and it will not absorb water. Little or no flame spread on the surface of PPFR panels was reported in laboratory tests [9].The presence of fibre in concrete improves heat resistance and prevents the destruction of the structure due to water vapour pressure [10]. The controlled cracking by polypropylene can be converted into useful economical advantage as less use of shrinkage steel, reduction in thickness of slab by up to $30 \%$ and ideal for joint free design [11].

f. Dosages: Many experimental works related to the use of polypropylene fibre in concrete have been published. In most cases, volume fractions of polypropylene fibre for this application ranged from $0.1 \%$ to $0.5 \%[12]$.

\section{g. Applications of poly propylene fibre:}

In the past several years, an increasing number of constructions have been taken place with concrete containing PPF such as foundation piles, prestressed piles, piers, highways, industrial floors, bridge decks, flotation units for walkways; it is also used for controlling shrinkage \& temperature cracking [3]. The main area of PPFRC applications includes buildings (slabs, beams, water storage tanks, pool construction, basements, architectural finishes, cement tiles and plastering, foundations, drainage etc.), bridges, highway pavements, industrial floorings, hydraulic structures, blast resistance, sewage and waste management and other applications include plaster to reduce plastic shrinkage cracking, increase abrasion resistance, increase freeze and thaw durability, control plastic settlement cracking etc. [4].

h. Cost of fibre: The higher initial cost by $15-20 \%$ is counterbalanced by the reduction in maintenance and rehabilitation operations [13].

\section{i. Fresh Properties of PPFRC:}

\section{Workability:}

The workability of Polypropylene fibre concrete has been found to decrease with increase in Polypropylene fibre content [4]. From laboratory studies of concretes containing about 0.1 percent by volume of PPF the results showed that adding fibre reduces the slump of concrete. Data from recent laboratory and field tests indicate slump losses ranging from $1 / 2$ inch to slightly over 3 inches, but there is little correlation between slump reduction and fibre length [14].With addition of fibre, the entrapped air voids increase and hence the increased air content reduces the workability causing difficulty in compaction of mixes. The fibre may also interfere and cause finishing problems [2]. Contractors are cautioned not to add water to restore lost slump; adding water won't improve workability but will reduce strength and increase shrinkage [14]. In PPFRC higher workability can be achieved with the addition of High Range Water Reducing admixtures [2] and [15].

\section{j. Hardened Properties of PPFRC:}

1. Compressive Strength:

Contradictory test results have been reported by different investigators regarding to the effects of polypropylene fibre on the compressive strength of concrete materials. Differences in results may have been caused by the differences in matrix composition, polypropylene fibre type and volume fraction and manufacturing conditions [16]. An example of the divergence of statistical test data, is given by comparison of work by Mindness\&Vondran, Hughes \&Fattuhi, whereby Mindness\&Vondran state compressive strength is increased by 25 percent at $0.5 \%$ volume fraction of PPF and Hughes \&Fattuhi state, compressive strength 
decreases with increase of PPF [17], [18].Alhozaimy et al carried out experimental investigations on the effects of adding low volume fractions $(<0.3 \%)$ of calculated fibrillated polypropylene fibres in concrete on compressive strength with different binder compositions. They observed that polypropylene fibres have no significant effect on compressive strength [19].

\section{The reasons of reduction in compressive strength:}

The compressive strengths of Polypropylene fibre mixtures are found to be less than that of PC The decrease in compressive strength may be because the presence of fibres introduces more air voids in the composite and also create consolidation and compaction problems and hence reduces the compressive strength of the mix [4]. The limits of reduction of strength with regard of air entrained concrete are defined by klieger who stated, "For moderate strength concrete, each percentile of entrained air reduces the compressive strength about 2 percent to 9 percent. Actual strength varies and is affected by the cementing materials source, admixture, and other concrete ingredients [20]. Super plasticizers, when added to fibre reinforced concrete, can lower water: cement ratios, and improve the strength [3].

\section{Modulus of elasticity:}

Elastic modulus of concrete containing $0.05 \%$ polypropylene is slightly higher than the elastic modulus of concrete without fibre. Addition of $0.10 \%$ and $0.20 \%$ polypropylene fibre not only did not improve the values of modulus of elasticity but also reduced it [21].

\section{Split Tensile Strength:}

In conventional concrete, specimen splits into two halves exactly under the loaded area, but using Fibre cylinders did not split into halves under the loaded area; Because of toughness it did not yield to sudden breakage [22].

Song et al noted an increase of $10 \%$ in the split tensile strength of fibre reinforced concrete at the fibre dosage of $0.6 \mathrm{~kg} / \mathrm{m}^{3}[23]$. While Ahmed et al studied that the tensile strength of concrete increases linearly with addition of fibres up to about $0.40 \%$ after which the tensile strength decreases with addition of more fibres. The tensile strength increases about $65 \%$ 70\% up to $0.40 \%$ after which it decreases. Tensile strength is increased due to bridging mechanism of polypropylene fibres and after certain time it reduced the bond strength between concrete ingredients so results in quick failure as compared to less volumes of fibres [11].

\section{The reasons of increasing in splitting tensile strength:}

Addition of fibre to a concrete mixture is beneficial to the tensile properties of concrete. Brittle matrices, such as plain mortar and concrete, lose their tensile load-carrying capacity almost immediately after formation of the first matrix crack[4]. It can be seen that the stress-displacement behaviour up to first crack is almost the similar for both PC and Polypropylene fibre; however the post-peak behaviour is different and the addition of Polypropylene fibres to concrete helps in increasing the post peak deformation capacity and enhancing the post-cracking strength of PPFRC in tension. In the case of PPFRC, the PP fibres come into action after the first crack. After the first crack occurs, the strength of the PC reduces immediately and the crack widening leads to the splitting of the cylinder. Once the splitting occurred and continued, the fibres bridging across the split portions of the matrix acted through the stress transfer from the matrix to the fibres and, thus, gradually supported the entire load. The PP fibres bridge these cracks and restrain them from further opening and hence improve the load-carrying capacity of structural member beyond cracking. The stress transfer improved the tensile strain capacity of the fibre-reinforced concrete and, therefore, increased the splitting tensile strength of the reinforced concretes over the unreinforced control counterpart After the first crack, a drop in the stress is noted which shows the stress transfer from concrete to the randomly distributer fibres, which further take the applied load by elongating [4].

\section{Effect of fibre length on splitting tensile strength:}

Vairagade et al studied the effect of length of fibre on the split tensile strength of fibre reinforced concrete and observed that, the split tensile strength of fibre reinforced concrete was dependent on length of fibre used. By addition of longer length fibre, the split tensile strength increases. Use of $24 \mathrm{~mm}$ long fibre with same volume of fraction gives maximum split tensile strength over fibre $15 \mathrm{~mm}$ and $20 \mathrm{~mm}$ cut length. The overall effect of $24 \mathrm{~mm}$ long fibre when used in fibre content of $0.25 \%$ of weight of cement was that, it improved the split tensile strength of concrete by $72 \%$ [24].

\section{Flexural Strength (Indirect Tensile)}

From laboratory studies of concretes containing about 0.1 percent by volume of polypropylene fibre, the results showed some increase in flexural strength is possible when fibre are added to concrete [14]. 


\section{The reasons of increasing in Flexural strength:}

Before the occurrence of the first crack, the load-deflection behaviour of all PPFRC beams was found to be similar to that of the control beams. Just after the appearance of the first crack, control beams suddenly failed and the load-defection behaviour showed a steep and sharp drop after the peak (maximum) load and thus exhibited little or no post-cracking deformation capacity. However in PPFRC beams, after the occurrence of the first crack, a drop is observed in the load-deflection curve as the load is released and transferred from the matrix to the fibres, and afterwards that the beams continues to withstand a portion of the load with increasing deformations and widening of the cracks. The PPFRC beams continue to resist load with increasing deformations by virtue of the elongation of the randomly distributed discrete fibres and ultimately fails at large deformations as the fibres reach their maximum elongation. The combined effect of the volume and the length of the fibre on the average flexure strength-displacement behaviour is that the PPFRC with the greatest volume and length showed the greatest vertical displacement [4].

a. Materials

\section{Experimental Program}

1. Cement: The cement used was ordinary Portland cement class $42.5 \mathrm{~N}$. Tests were conducted and Verified according to BS EN 196-3:2005, BS EN 197-1:2000 and BS EN 196-1:2005 requirements.

Table 1: Results of tests on cement

\begin{tabular}{|l|l|l|}
\hline Tests & Results & Requirements of BS EN \\
\hline Normal Consistency \% & $30.25 \%$ & $25 \%-33 \%$ \\
\hline Setting time (min) & & \\
Initial Setting time test & 160 & Not Less than $60 \mathrm{~min}$ \\
Final Setting time test & 238 & Not More than $390 \mathrm{~min}$ \\
\hline Specific gravity & 3.15 & \\
\hline
\end{tabular}

\section{Aggregate}

Tests were conducted and Verified according to BS 882: 1992.

Fine Aggregate (sand): Good Quality of river natural Sand was used as a fine aggregate.

Table 2: Results of tests on Fine Aggregate

\begin{tabular}{|l|l|}
\hline Tests & Results \\
\hline Fineness Modulus & 2.91 \\
\hline Silt Content & $4 \%$ \\
\hline Water absorption & $2 \%$ \\
\hline Specific gravity & 2.6 \\
\hline Bulk Density & $1632 \mathrm{~kg} / \mathrm{m}^{3}$ \\
\hline Voids Ratio & 0.37 \\
\hline
\end{tabular}

Coarse Aggregate: The coarse aggregate used is natural uncrushed of maximum size $20 \mathrm{~mm}$.

Table 3: Results of Tests on Coarse Aggregate

\begin{tabular}{|l|l|}
\hline Test Conducted & Results \\
\hline Water absorption & $0.2 \%$ \\
\hline Specific gravity & 2.6 \\
\hline Bulk Density & $1644 \mathrm{~kg} / \mathrm{m}^{3}$ \\
\hline Voids Ratio & 0.37 \\
\hline
\end{tabular}

\section{Water}

To mix the ingredients of concrete Tap water has been used.

4. Admixtures

Super plasticizer without retarding was used to obtain adequate workability (SP903 confirms to ASTM C-494-Type F, B.S 5075- Part 1, ASTMC1017). The recommended dosage range is 0.2-2.5\% of mass cement. Super plasticizer was produced in Sudan by SERAPHIM Concrete Additives Company. 


\section{Polypropylene Fibre}

In this experimental work monofilament fibre of length $12 \mathrm{~mm}$ was used. Fibre was produced in England by ADFIL Construction Fibres Company.

Table 4: Data of polypropylene fibre

\begin{tabular}{|l|l|}
\hline Material & Polypropylene fiber \\
\hline Density $\mathrm{g} / \mathrm{m}^{3}$ & 910 \\
\hline Length $\mathrm{mm}$ & 12 \\
\hline Design & Monofilament Fiber \\
\hline Absorption & Nil \\
\hline Thermal Conductivity & Low \\
\hline Acid resistance & High \\
\hline Colour & Natural \\
\hline Melt Point & $160^{\circ} \mathrm{c}$ \\
\hline
\end{tabular}

\section{Mix Design According to British Department of Environment (DOE)}

\section{Test Data:}

1- Grade designation C30

2- Type of Cement: Ordinary Portland Cement

3- Min Cement Content: $300 \mathrm{~kg} / \mathrm{m}^{3}$

4- Max W/C ratio: 0.6

5- Type of Aggregate: Uncrushed

6- Max nominal size of the aggregate: $20 \mathrm{~mm}$

7- Slump 60-120mm

8- Super plasticizer was varied to maintain the slump for all mixtures.

9- Percentage of passing $600 \mu \mathrm{m}$ sieve $=32.79 \%$

10- Three different fibre percentages of $0.1 \%, 0.3 \%$ and $0.5 \%$ by volume of concrete were used.

\section{Target mean strength $=39.84 \mathrm{~N} / \mathrm{mm}^{2}$}

Table 5: Mix Proportions

\begin{tabular}{|l|l|l|l|l|l|l|l|l|}
\hline Mix No. & $\begin{array}{l}\text { Fibre } \\
\text { content } \\
\left(\mathbf{k g} / \mathbf{m}^{\mathbf{3}}\right)\end{array}$ & $\begin{array}{l}\text { Fibre } \\
\text { length } \\
(\mathbf{m m})\end{array}$ & $\begin{array}{l}\text { Cement } \\
\mathbf{c o n t e n t} \\
\left(\mathbf{k g} / \mathbf{m}^{\mathbf{3}}\right)\end{array}$ & $\begin{array}{l}\text { Water } \\
\text { content } \\
\left(\mathbf{k g} / \mathbf{m}^{\mathbf{3}}\right)\end{array}$ & $\begin{array}{l}\text { Fine } \\
\text { Aggregate } \\
\left(\mathbf{k g} / \mathbf{m}^{\mathbf{3}}\right)\end{array}$ & $\begin{array}{l}\text { Coarse } \\
\text { Aggregate } \\
\left(\mathbf{k g} / \mathbf{m}^{\mathbf{3}}\right)\end{array}$ & $\begin{array}{l}\text { W/C } \\
\text { Ratio }\end{array}$ & $\begin{array}{l}\text { Super- } \\
\text { plasticizer } \\
\left(\mathbf{k g} / \mathbf{m}^{\mathbf{3}}\right)\end{array}$ \\
\hline Control & 0 & 0 & 375 & 195 & 767 & 1017 & 0.52 & 1.4 \\
\hline $\mathbf{0 . 1 \%}$ & 0.9 & 12 & 375 & 195 & 767 & 1017 & 0.52 & 1.8 \\
\hline $\mathbf{0 . 3 \%}$ & 2.7 & 12 & 375 & 195 & 767 & 1017 & 0.52 & 2.4 \\
\hline $\mathbf{0 . 5 \%}$ & 4.5 & 12 & 375 & 195 & 767 & 1017 & 0.52 & 4 \\
\hline
\end{tabular}

The total mixing time was 5 minutes; the samples were then casted in steel moulds and compacted, then left for 24 hours before demoulding, then they were placed in the curing tank of $20 \pm 2^{\circ} \mathrm{C}$. Water absorption of coarse and fine aggregate was taken into consideration

\section{b. Test Methods}

\section{Fresh Properties} Slump test:

Experimental investigation of fresh mix Properties was conducted based on BS 1881-102: 1983 using a slump cone of $305 \mathrm{~mm}$ high. The base of $203 \mathrm{~mm}$ diameter is placed on a smooth surface with the smaller opening of $102 \mathrm{~mm}$ diameter at the top, and the container is filled with concrete in three layers. Each layer is tamped 25 times with a standard $16 \mathrm{~mm}$ diameter steel rod, rounded at the end, and the top surface is struck off.

\section{Hardened Properties:}

\section{Compressive Strength test:}

The test was conducted according to BS EN 12390. The universal testing machine of 1500Kn capacity was used for testing the compressive strengths of nine $150 \times 150 \times 150 \mathrm{~mm}$ cube specimens at 7,14 , and 28 days from casting for each mix. The load was applied on the cube at a constant rate of stress equal to 0.2 to $0.4 \mathrm{MPa} / \mathrm{second}$. The compressive strength interpreted by stress generated from the result of compression load 
per area of specimen surface. The results for each specimen are based on an average value of three replicate specimens.
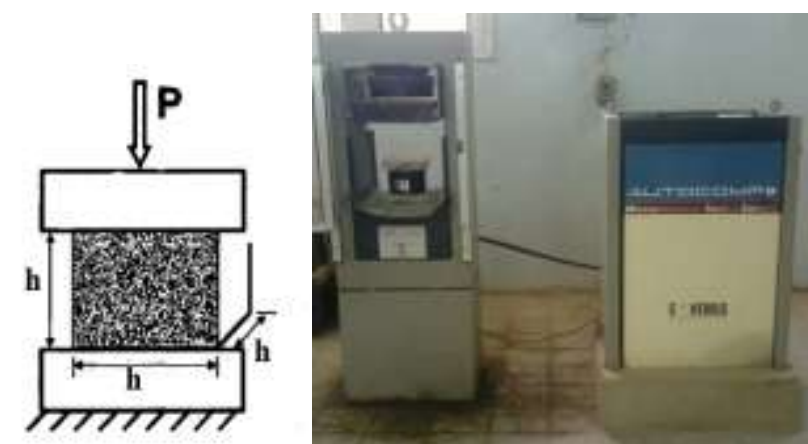

Figure 2: Compressive strngth test apparatusFlexural Strength test

\section{Flexural Strength test:}

Flexural strength (at 28 days of curing) test was conducted according to the requirements of BS EN 12390-5:2000 using three $100 \times 100 \times 500 \mathrm{~mm}$ beams under third-point loading on a simply supported span of $400 \mathrm{~mm}$. The load was applied at constant rate of loading within the range $0.04 \mathrm{MPa} / \mathrm{s}\left(\mathrm{N} / \mathrm{mm}^{2} \mathrm{x} \mathrm{s}\right)$ to 0.06 $\mathrm{MPa} / \mathrm{s}\left(\mathrm{N} / \mathrm{mm}^{2} \mathrm{x} \mathrm{s}\right)$. The load was applied without shock and increase continuously, at the selected constant rate $\pm 1 \%$, until no greater load can be sustained.According to BS EN 12390-5:2000 standard, the results of flexural strength test is interpreted by calculating flexural stress as following:

$$
\mathrm{R}=\mathrm{PL} / \mathrm{bd}^{2} \text {. }
$$

Where: $\mathrm{R}$ is flexural strength (modulus of rupture), $\mathrm{P}$ is maximum indicated load, $\mathrm{L}$ is span length, $\mathrm{b}$ is width of specimen, and $\mathrm{d}$ is depth of the specimen.

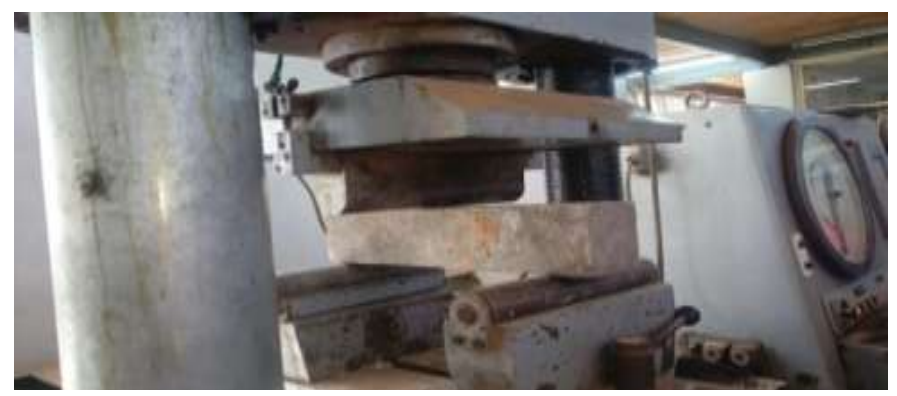

Figure 3: flexural strength test apparatus

\section{Splitting Tensile Strength test:}

Split tensile strength (at 28 days of curing) test of three $150 \times 300 \mathrm{~mm}$ cylinders is indirect measurement of tensile strength of concrete which were conducted according to the requirements of BS EN 12390-6:2009.

In the split tensile strength test, cylindrical concrete specimen is placed on diametrical compressive force along its length. The load is applied continuously at a constant rate until failure of cylinder along its vertical diameter. To allow the uniform distribution of applied compressive load, strips of plywood are placed between the specimen and loading platens of the testing machine. The load was applied at constant rate of loading within the range $0.04 \mathrm{MPa} / \mathrm{s}\left(\mathrm{N} / \mathrm{mm}^{2} \times\right.$ s) to $0.06 \mathrm{MPa} / \mathrm{s}\left(\mathrm{N} / \mathrm{mm}^{2} \mathrm{x} \mathrm{s}\right)$. Apply the load without shock and increase continuously, at the selected constant rate $\pm 1 \%$, until no greater load can be sustained.

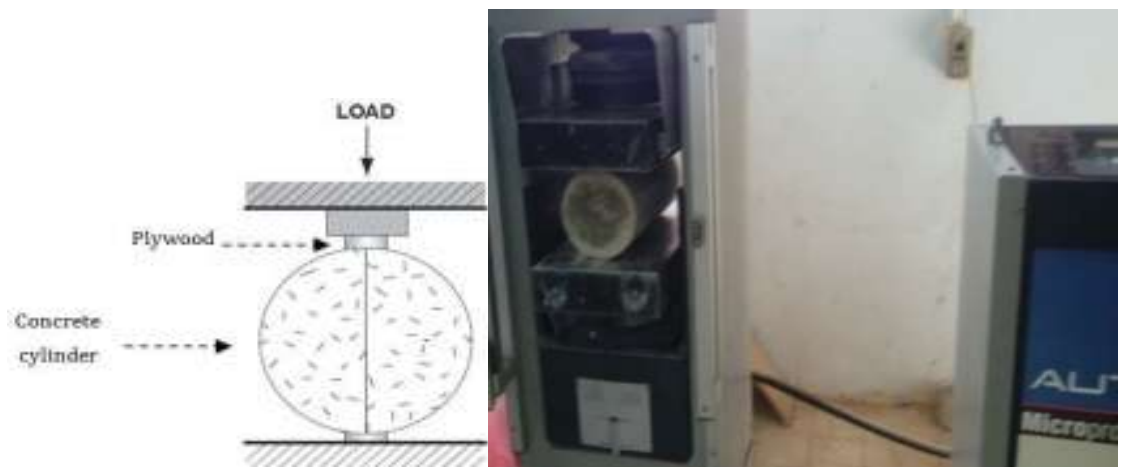

Figure 4: Splitting tensile strength test apparatus 
Splitting tensile strength of a specimen can be calculated from the equation: $\mathrm{T}=2 \mathrm{P} /\left(\pi^{*} 1 * \mathrm{~d}\right)$

Where: $\mathrm{T}$ is tensile strength, $\mathrm{P}$ is compression load at failure, 1 is length of cylinder, and $\mathrm{d}$ is diameter of the cylinder.

\section{Resonance frequency meter test:}

Modulus of elasticity of concrete was measured after 28 day of curing for three $150 \times 300 \mathrm{~mm}$ cylinders using Resonance frequency meter.The cylinders were drilled at the center of cross section and connected to the Resonance frequency meterapparatus as shown in figure (5). The cylinder was slightly knocked on the other end to transverse the frequencies to the apparatus and modulus of elasticity was calculated using the software build in the apparatus.

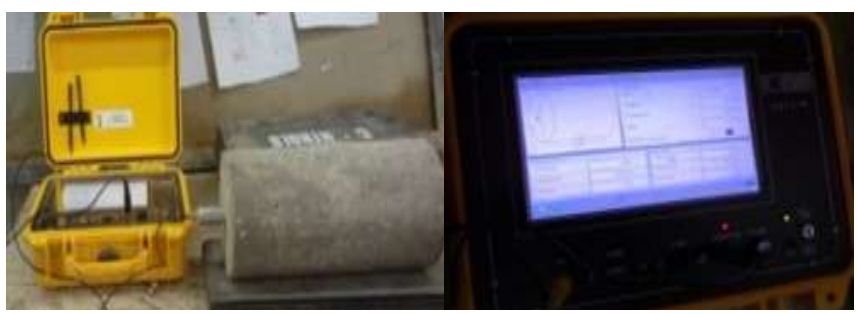

Figure 5: Resonance frequency meter apparatus

\section{Results And Discussion}

Fresh properties represented by workability (slump) test, while hardened properties represented by compressive strength test at 7, 14 and 28 days of curing, flexural and tensile strength as well as modulus of elasticity at 28 days of curing for each mix.

\section{A. Fresh properties}

Comparison of the measured slump of the fresh concrete mixes can be observed in table (6) and figure (6).Test results of slump of control mix and polypropylene fibre concrete mixes show that PPFRC mixtures reduces the slump values which were needed to ascertain adequate workability of the fresh concrete to be placed and finished. In order to maintain reasonable slump without change in $\mathrm{w} / \mathrm{c}$ ratio of the mix, the super plasticizer admixture was used. Segregation and reduction in strength will occur if only water content was increased to increase the workability.It was observed that the dosages of super plasticizer had been increased with the increase in PPF percentages. These results coincide with the most of the previous studies in PPFRC behaviour [14], [4].

Table 6: Effect of polypropylene fibre on slump and effect of increase in super plasticizer dosages in improve the workability of polypropylene fibre.

\begin{tabular}{|c|c|c|c|c|}
\hline $\begin{array}{c}\text { Volume of } \\
\text { Polypropylene \% }\end{array}$ & $\begin{array}{c}\text { Super- } \\
\text { plasticizer } \\
\left(\mathbf{K g} / \mathbf{m}^{3}\right)\end{array}$ & $\begin{array}{c}\text { Slump test } \\
\text { results }(\mathbf{m m})\end{array}$ & $\begin{array}{c}\text { Increases in Super-plasticizer } \\
\text { dosages to get the adequate } \\
\text { slump for PPF }\left(\mathbf{K g} / \mathbf{m}^{3}\right)\end{array}$ & $\begin{array}{c}\text { Slump test results } \\
(\mathbf{m m}) \text { after } \\
\text { increase in S.P }\end{array}$ \\
\hline 0 & 1.4 & 120 & 1.4 & 120 \\
\hline 0.1 & 1.4 & 40 & 1.8 & 80 \\
\hline 0.3 & 1.4 & 30 & 2.4 & 70 \\
\hline 0.5 & 1.4 & 10 & 4 & 70 \\
\hline
\end{tabular}

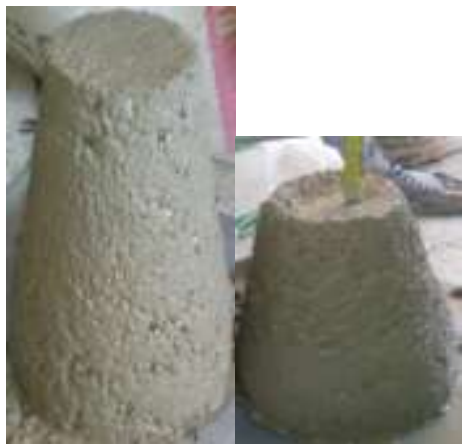

Figure 6: Slump tests for (i) polypropylene fibre without increase in super plasticizer dosages. (ii) Polypropylene fibre with increase in super plasticizer dosages. 


\section{B. Hardened Concrete Properties}

In order to evaluate the effects of polypropylene fibre on hardened properties of concrete; compressive, splitting tensile and flexural strength and modulus of elasticity of concrete specimens have been tested.

\section{Compressive strength}

Nine cubes of $150 * 150 * 150 \mathrm{~mm}$ were tested at 7, 14, 28 days for control mix and different volume percentages of polypropylene fibre concrete $(0.1 \%, 0.3 \%$ and $0.5 \%)$. The following tables (7) and Figures (7), (8) and (9) show test results.It's clear from table (7) and figures (7), (8) that a little reduction in compressive strength of PPFRC mixtures was observed at 7 and 28 days for all volume percentages of fibre compared to control mix. This reduction attributed to the presence of fibre in the concrete which affect the compaction of concrete and introduce more air voids. The reduction percentages range from $1 \%$ to $2 \%$. The results coincide with pervious study in effect of PPFRC in compressive strength [4].

14 days result of PPFRC in table (7) showed an increase in compressive strength of concrete for $0.1 \%$ and $0.3 \%$ of fibre about $7 \%$ and $4 \%$ respectively, after that compressive strength reduce to reach $9 \%$ less than control mix at $0.5 \%$ fibre percentage.Figure (9) shows the pattern of failure of cubes which coincide with the previous study of Fatima [4].Fatima stated that the fibres tend to increase the ductility of the mix by increasing the failure strains. The smallerstrain of control mix is because of the fact that after the concrete reaches its peak stress; cracks appear and as the loading continues the failure is occurred by the crushing of the concrete specimen at a relatively lower value of strain. However in PPFRC mixtures the increase in strains is due to the fact that these fibres have an interlocking capability which allows these to hold the mixture together even after cracking and so prevent the shattering force. In PPFRC specimens, the bulging of specimens was observed without any significant deterioration of the test specimen.

Table 7: Compressive strength results for control mix and different polypropylene volume percentages after 7,14 and 28 days.

\begin{tabular}{|c|c|c|c|c|}
\hline \multirow{2}{*}{ Test Date } & \multicolumn{4}{|c|}{ Compressive Strength N/mm ${ }^{2}$} \\
\cline { 2 - 5 } & Control mix & $\mathbf{0 . 1 \%}$ Polypropylene & $\mathbf{0 . 3 \%}$ Polypropylene & 0.5\% Polypropylene \\
\hline 7 days & 36.23 & 35.8 & 35.4 & 35.33 \\
\hline 14 days & 38.23 & 40.8 & 39.77 & 34.67 \\
\hline 28 days & 42.6 & 42.2 & 42.1 & 42.1 \\
\hline
\end{tabular}

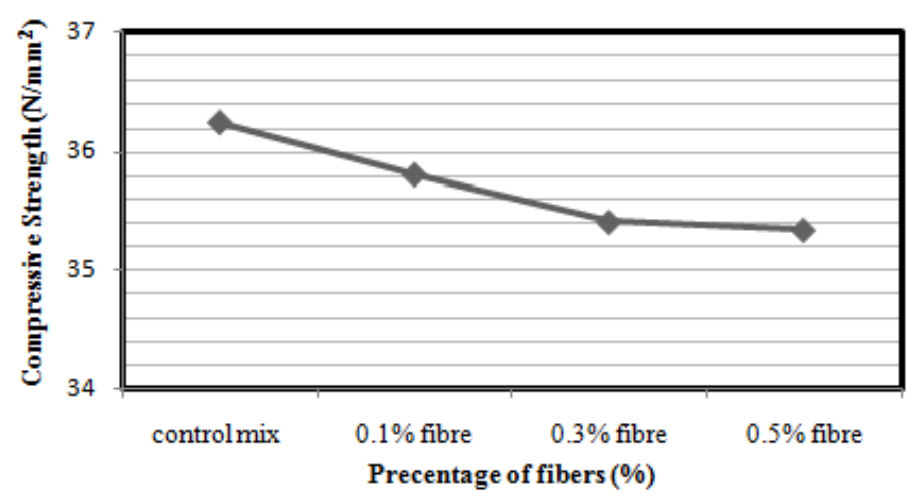

Figure 7: Relationship between compressive strength and fibre percentages after 7 days

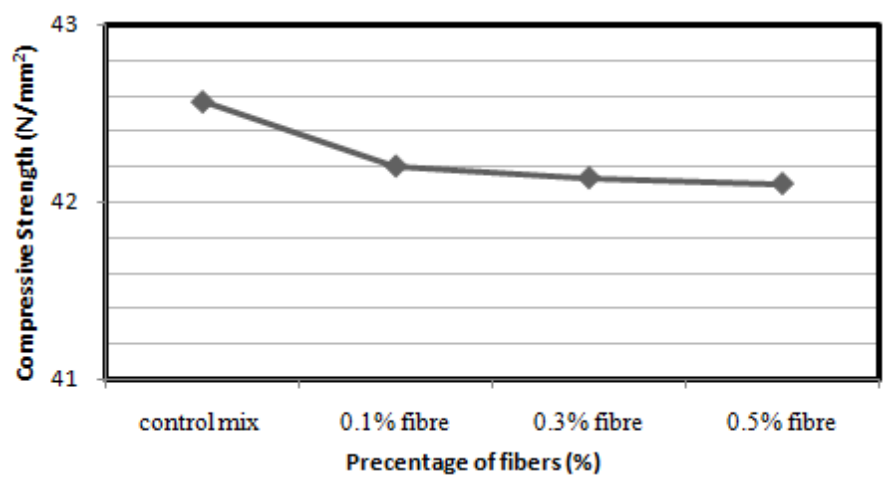

Figure 8: Relationship between compressive strength and fibre percentages after 28 days 


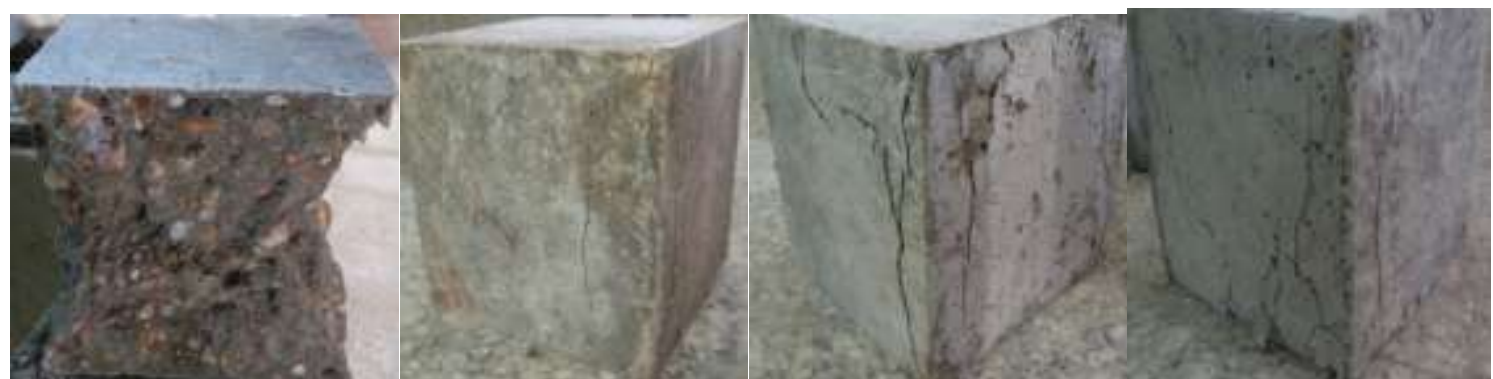

Figure 9: Failure Pattern of control and polypropylene fibre cubes under compressive strength test after 14 days.

\section{Modulus of elasticity}

Three cylinders specimens of $300 * 150 \mathrm{~mm}$ have been tested at 28 day after curing for control mix and each volume percentages of polypropylene fibre concrete $(0.1 \%, 0.3 \%$ and $0.5 \%)$. Table (8) and figure (10) show the results of the tests. Reduction in modulus of elasticity of PPFRC mixtures was observed for all volume percentages of fibre when compared to control mix. This reduction may be because modulus of elasticity has a positive relationship with the compressive strength of concrete. As PPFRC increase the modulus of elasticity decrease, the reduction percentage ranges from $2 \%$, to $9 \%$.

Table 8: Test result for hardened properties of control mix and different polypropylene volume percentages

\begin{tabular}{|c|c|c|c|c|}
\hline Tests & Control mix & $\mathbf{0 . 1 \%}$ Polypropylene & $\mathbf{0 . 3 \%}$ Polypropylene & $\mathbf{0 . 5 \%}$ Polypropylene \\
\hline Modulus of elasticity (GPa) & 46.6 & 45.6 & 43.4 & 42.5 \\
\hline Tensile Strength $\left(\mathbf{N} / \mathbf{m m}^{2}\right)$ & 2.4 & 3 & 3.4 & 3 \\
\hline Flexural strength $\mathbf{~ N / m ^ { 2 } )}$ & 6.82 & 6.83 & 5.93 & 7.4 \\
\hline
\end{tabular}

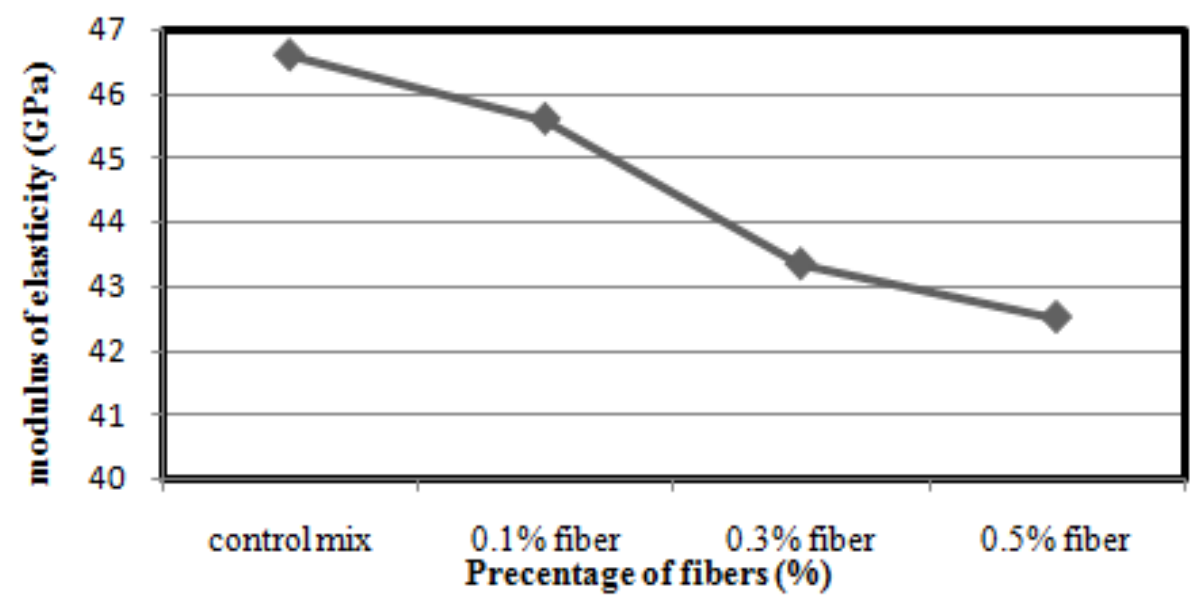

Figure 10: Relationship between modulus of elasticity and different fibre percentages

\section{Splitting tensile strength}

Three cylinders specimens of $300 * 150 \mathrm{~mm}$ have been tested at 28 day for control mix and each volume percentages of polypropylene fibre concrete $(0.1 \%, 0.3 \%$ and $0.5 \%)$. Table (8) and Figure (11), (12) show the test results.Results show significant improvement in splitting tensile strength for all percentages of PPFRC. Results agreed with the previous studies [11] and [4].In the case of PPFRC, the PPF come into action after the first crack the PPF bridges these cracks and restrain them from further opening and hence improve the load carrying capacity of structural member beyond cracking. After the first crack, a drop in the stress is noted which shows the stress transfer from concrete to the randomly distributed fibres, which further take the applied load by elongating. The percentage of increasing ranges from $25 \%$ to $42 \%$ for $0.1 \%$ and $0.3 \%$ fibre volume percentages after that at $0.5 \%$ percentage the tensile strength start to decrease but it was also greater than the control mix by $25 \%$. 


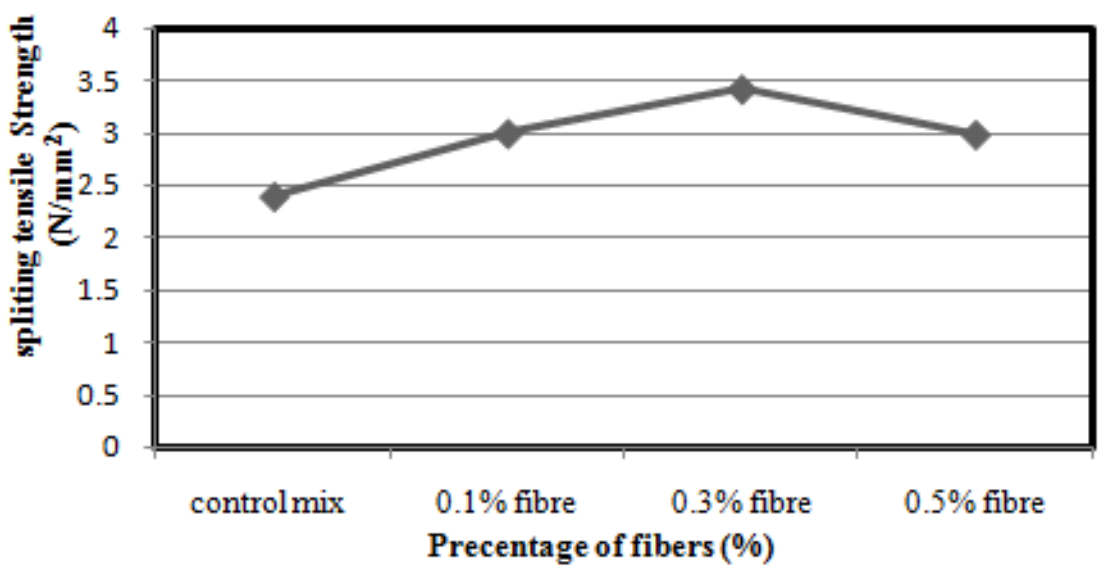

Figure 11: Relationship between splitting tensile strength and different fibre percentages.

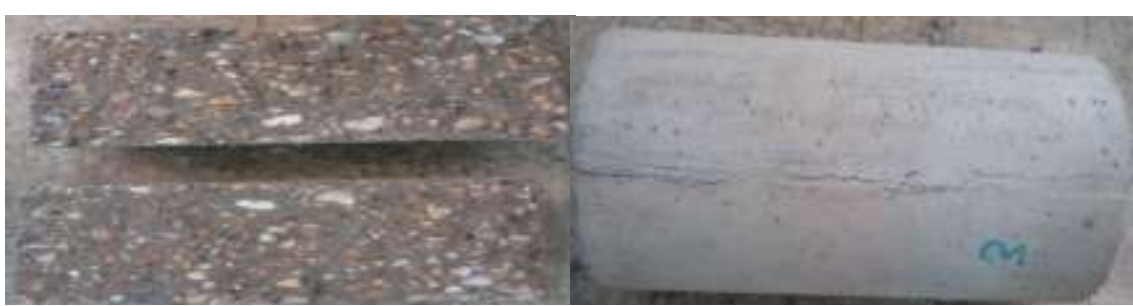

Figure 12: Failure Pattern of control and polypropylene fibre cylinders under the split tensile strength test.

\section{Flexural strength}

Three beams specimens of $100 * 100 * 500 \mathrm{~mm}$ have been tested at 28 day after curing for control mix and each volume percentages of polypropylene fibre concrete $(0.1 \%, 0.3 \%$ and $0.5 \%)$. Table (8) and Figure (13), (14) shows test results.Results show significant improvement in flexural strength at $0.5 \%$ PPF volume percentage. This result interpreted previously by Fatima [4].Unexpected reduction of $13 \%$ in flexural strength was observed at $0.3 \%$ dosage of PPF; this may refer to bad quality control in laboratory.

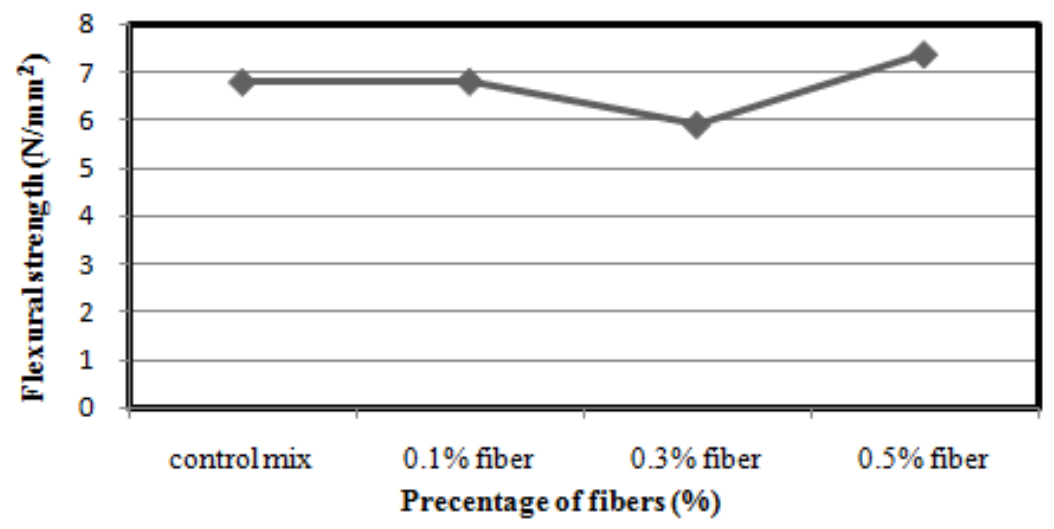

Figure 13: Relationship between flexural strength and different fibre percentages

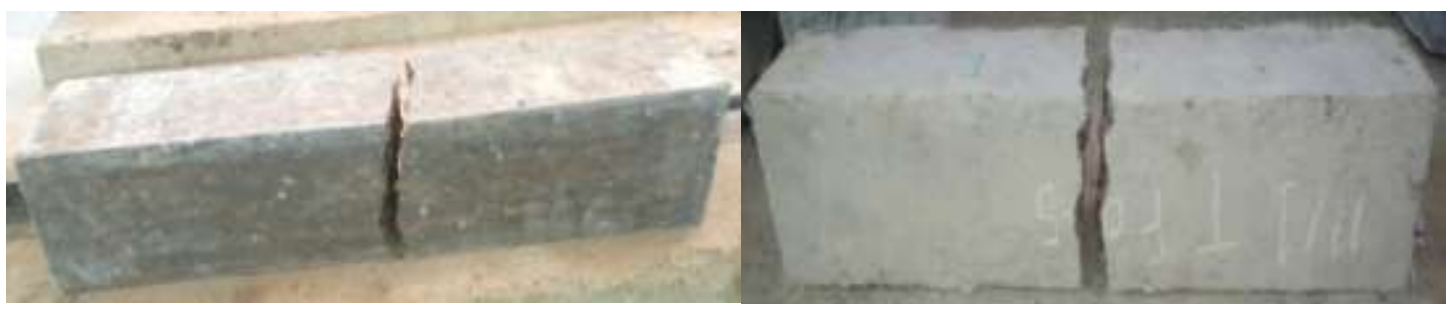

Figure 14: Failure Pattern of control and polypropylene fibre beam 


\section{Conclusions and Recommendations}

\section{Conclusions}

1- In fresh state, when the volume of polypropylene fibre increased it caused reduction in workability and the mix became fibrous which results difficulty in handling.

2- Modulus of elasticity of polypropylene fibre concrete at 28 day was found to decrease (about $2 \%$ to $9 \%$ ) with increase in fibre percentages.

3- Flexural strength at 28 day was increased for $0.5 \%$ volume percentage of PPFRC by $9 \%$, a reduction in flexural strength at $0.3 \%$ occurred due to bad quality control in laboratory.

4- Strength enhancement in splitting tensile strength at 28 day due to polypropylene fibre addition varies from $25 \%$ to $42 \%$.

\section{Recommendations}

1- The current construction industry demand new types of concrete are to be invented, which will satisfy the problems observed in traditional concrete. In this approach PPFRC will be a good substitute to meet the present demand of construction industry.

2- Transfer of what has been learned regarding FRC to the engineering community has suffered from a basic lack of specifications and standards in the field of engineering materials science.

3- Quality control, mixing and compaction procedure should be carefully considered when using polypropylene fibre mixes.

4- Polypropylene fibrebehaviour is complicated and need to study more than three volume percentages to understand its exact behaviour.

5- This study was conducted on plain concrete. Beneficial effects of PPF on reinforced concrete for structural applications should also be studied.

\section{References}

[1] ACI 544.3R-08, 2008, 'Guide for Specifying, Proportioning and Production of Fibre Reinforced Concrete'.

[2] Madhavi, T.CH, Raju, L.S, Mathur, D 2014, 'Polypropylene Fibre Reinforced Concrete-A Review', International Journal of Emerging Technology and Advanced Engineering (ijetae), Vol.4, No.4, p.114-119.

[3] Singh, S.K, 2010, 'Polypropylene Fibre Reinforced Concrete, an overview',Central Building Research Institute, Roorkee\& Honorary Secretary Institute of Engineers, Roorkee.

[4] Fatima, S 2013, 'Mechanical properties of polypropylene fibre reinforced concrete (PPFRC) and structural applications', NED University of Engineering and Technology, Karachi.

[5] Wafa, F.F1990, 'Properties and Applications of Fibre Reinforced Concrete', Engineering Sciences Journal, vol.2, No.1, p.49-63.

[6] Patel, M.J \&Kulkarni, S.M 2013, 'Effect of PolyproplyeneFibre on the High Strength Concrete', Journal of Information, Knowledge and Research in Civil Engineering, Vol.2, No.2, p.125-129.

[7] Banthia, N \&Gupta, R 2006, 'Influence of polypropylene fibre geometry on plastic shrinkage cracking in concrete',Cement and Concrete Research, Elsevier publisher, Vol.36, No.7, p.1263-1267.

[8] Mohod, M.V \&Meghe, R2015, 'Performance of Polypropylene Fibre Reinforced Concrete',IOSR Journal of Mechanical and Civil Engineering (IOSR-JMCE), Vol.12, No.1, p.28-36.

[9] 'Concrete Construction', 'Concrete Reinforced with PolypropyleneFibres',viewed 1June1983, http:// www. Concreteconstr uction.net/

[10] Ahmadipourinaeim, S.H \&Saberi, Y2014, 'Study on the Effect of Polypropylene Fibres on Strength and Heat Resistance of Concrete', World Applied Sciences Journal, vol.31, No.5, p.767-770.

[11] Ahmed, S, Bukhari, I.A, Siddiqui J.I \&Qureshi, S.A2006, 'A study on properties of polypropylene fibre reinforced concrete', University of Engineering \& Technology, Taxila, Pakistan, 31st Conference on our world in concrete \&structures, 16-17 august2006, Singapore.

[12] Toutanji, H, Mcneil, S \&Bayasi, Z 1998, 'Chloride permeability and impact resistance of polypropylene-fibrereinforced silica fume concrete', Cement and Concrete Research, vol.28, No.7, p.961-9688.

[13] Kanalli, S.A, Palankar, R, Kumar, B, Kumar, P \&Prakash, S.K 2014, 'Comparative Study of Polymer Fibre Reinforced Concrete With Conventional Concrete', International Journal of Research in Engineering and Technology, Vol.3, No. 1, p.139-143

[14] Malisch, W. R 1986, 'Polypropylene Fibres in Concrete, What do the test tell us?',http://www.concreteconstruction.net.

[15] Thirumurugan, S \&SivaKumar, A 2013, 'Compressive Strength Index of Crimped Polypropylene Fibres in High Strength Cementitious Matrix’, World Applied Sciences Journal, vol. 24, No.6, p.698-702.

[16] Alhozaimy, A. M, Soroushian, P \&Mirza, F 1996, 'Mechanical properties of polypropylene fibre reinforced concrete and the effects of pozzolanic materials', Cement and Concrete Composites, vol.18, No.2,p.85-92.

[17] Mindess, S \&Vondran, G 1988, 'Properties of concrete reinforced with fibrillated polypropylene fibres under impact loading', Cement and Concrete Research, vol.18, No.1, p.109-115.

[18] Hughes, B. P \&Fattuhi, N. I 1976, 'Improving the toughness of high strength cement paste with fibre reinforcement', Composites, vol.7, No.3, p.185-188. 
[19] Alhozaimy, A. M, Soroushian, P \&Mirza, F 1995, 'Plastic Shrinkage Cracking of Polypropylene Fibre Reinforced Concrete’, ACI Materials Journal, Vol. 92, No.5, p.553-560.

[20] Klieger, P 1956, 'Further Studies on the Effect of Entrained Air on Strength and Durability of Concrete with various Sizes of Aggregates', Bulletin 77, Research and Development laboratories of the Portland Cement Association, Portland, OR.

[21] Karahan, O \&Atiş, C.D 2011, 'The durability properties of polypropylene fibre reinforced fly ash concrete', Materials and Design,Elsevier publisher, Vol. 32, p.1044-1049.

[22] Selvi, M. T, Thandavamoorthy, T.S 2013, 'Studies on the Properties of Steel and Polypropylene Fibre Reinforced Concrete without any Admixture', International Journal of Engineering and Innovative Technology (IJEIT), Vol. 3, No.1, p. 411-416.

[23] Vairagade, V.S, Kene, K.S \&Deshpande, N.V 2012, 'Investigation on Compressive and Tensile Behavior of Fibrillated Polypropylene Fibres Reinforced Concrete', International Journal of Engineering Research and Applications (IJERA), Vol. 2, No.3, p.1111-1115

[24] Song, P.S, Hwang, S \&Sheu, B.C 2005, 'Strength properties of nylon- and polypropylene-fibre reinforced concretes', Cement And Concrete Research, vol.35, No.8, p.1546-1550. 